\title{
TU/e EmHOONEN

\section{Friction factor estimation for turbulent flows in corrugated pipes with rough walls}

\section{Citation for published version (APA):}

Pisarenco, M., Linden, van der, B. J., Tijsseling, A. S., Ory, E., \& Dam, J. A. M. (2009). Friction factor estimation for turbulent flows in corrugated pipes with rough walls. (CASA-report; Vol. 0915). Technische Universiteit Eindhoven.

\section{Document status and date:}

Published: 01/01/2009

\section{Document Version:}

Publisher's PDF, also known as Version of Record (includes final page, issue and volume numbers)

\section{Please check the document version of this publication:}

- A submitted manuscript is the version of the article upon submission and before peer-review. There can be important differences between the submitted version and the official published version of record. People interested in the research are advised to contact the author for the final version of the publication, or visit the $\mathrm{DOI}$ to the publisher's website.

- The final author version and the galley proof are versions of the publication after peer review.

- The final published version features the final layout of the paper including the volume, issue and page numbers.

Link to publication

\section{General rights}

Copyright and moral rights for the publications made accessible in the public portal are retained by the authors and/or other copyright owners and it is a condition of accessing publications that users recognise and abide by the legal requirements associated with these rights.

- Users may download and print one copy of any publication from the public portal for the purpose of private study or research.

- You may not further distribute the material or use it for any profit-making activity or commercial gain

- You may freely distribute the URL identifying the publication in the public portal.

If the publication is distributed under the terms of Article 25fa of the Dutch Copyright Act, indicated by the "Taverne" license above, please follow below link for the End User Agreement:

www.tue.nl/taverne

Take down policy

If you believe that this document breaches copyright please contact us at:

openaccess@tue.nl

providing details and we will investigate your claim. 


\section{EINDHOVEN UNIVERSITY OF TECHNOLOGY}

Department of Mathematics and Computer Science

\section{CASA-Report 09-15 \\ May 2009}

Friction factor estimation for turbulent flows

in corrugated pipes with rough walls

$$
\text { by }
$$

M. Pisarenco, B.J. van der Linden, A.S. Tijssseling, E. Ory, J.A.M. Dam

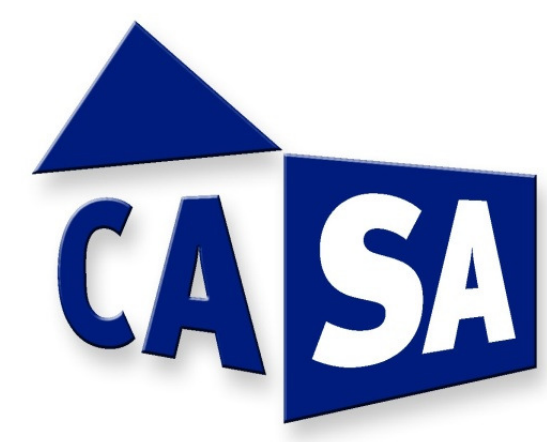

Centre for Analysis, Scientific computing and Applications

Department of Mathematics and Computer Science

Eindhoven University of Technology

P.O. Box 513

5600 MB Eindhoven, The Netherlands

ISSN: 0926-4507 



\section{CASA Report 2009-15}

\section{FRICTION FACTOR ESTIMATION FOR TURBULENT FLOWS IN CORRUGATED PIPES WITH ROUGH WALLS}

\author{
Maxim Pisarenco * \\ Dept. of Math. and Comp. Science \\ Eindhoven University of Technology \\ P.O. Box 513, $5600 \mathrm{MB}$ Eindhoven \\ The Netherlands \\ Email: m.pisarenco@tue.nl
}

\author{
Bas van der Linden \\ Dept. of Math. and Comp. Science \\ Eindhoven University of Technology \\ P.O. Box 513, 5600 MB Eindhoven \\ The Netherlands \\ Email: b.j.v.d.linden@tue.nl
}

\author{
Arris Tijsseling \\ Dept. of Math. and Comp. Science \\ Eindhoven University of Technology \\ P.O. Box 513, 5600 MB Eindhoven \\ The Netherlands \\ Email: a.s.tijsseling@tue.nl
}

\author{
Emmanuel Ory \\ Single Buoy Moorings Inc. \\ P.O. Box 199, MC 98007 Monaco Cedex \\ Monaco \\ Email: emmanuel.ory@singlebuoy.com
}

\author{
Jacques Dam \\ Stork Inoteq \\ P.O. Box 379, 1000 AJ Amsterdam \\ The Netherlands \\ Email: jacques.dam@stork.nl
}

\section{ABSTRACT}

The motivation of the investigation is critical pressure loss in cryogenic flexible hoses used for LNG transport in offshore installations. Our main goal is to estimate the friction factor for the turbulent flow in this type of pipes. For this purpose, twoequation turbulence models $(k-\varepsilon$ and $k-\omega)$ are used in the computations.

First, fully developed turbulent flow in a conventional pipe is considered. Simulations are performed to validate the chosen models, boundary conditions and computational grids. Then a new boundary condition is implemented based on the "combined" law of the wall. It enables us to model the effects of roughness (and maintain the right flow behavior for moderate Reynolds numbers). The implemented boundary condition is validated by comparison with experimental data.

Next, turbulent flow in periodically corrugated (flexible) pipes is considered. New flow phenomena (such as flow separation) caused by the corrugation are pointed out and the essence of periodically fully developed flow is explained. The friction factor for different values of relative roughness of the fabric is estimated by performing a set of simulations. Finally, the main conclusion is presented: the friction factor in a flexible corru-

*Address all correspondence to this author. gated pipe is mostly determined by the shape and size of the steel spiral, and not by the type of the fabric which is wrapped around the spiral.

Keywords: flexible pipe, friction factor, roughness modeling, corrugated pipe, modified law of the wall.

\section{INTRODUCTION}

Non-metallic flexible pipe products have found wide usage in industry. Areas of application include heating, ventilation, air-conditioning and, most importantly, connecting terminal or delivery devices to main distribution ducts (such as transport of Liquid Natural Gas from ships to the mainland distribution network).

Flexible ducts are often comprised of fabric wrapped over a spiral metal framework. Due to this construction, they respond very well to bending, are cheaper and much easier to install than metal pipes. Figure 1 shows a typical flexible pipe. It is constructed from a neoprene impregnated polyester fabric encapsulating a helix spring of steel wire. This tube has an excellent strength/weight ratio and is able to withstand severe flexing. The steel spiral wire gives strength to the pipe, while the use of fabric instead of a hard material (such as metal) allows for a high degree of flexibility. 


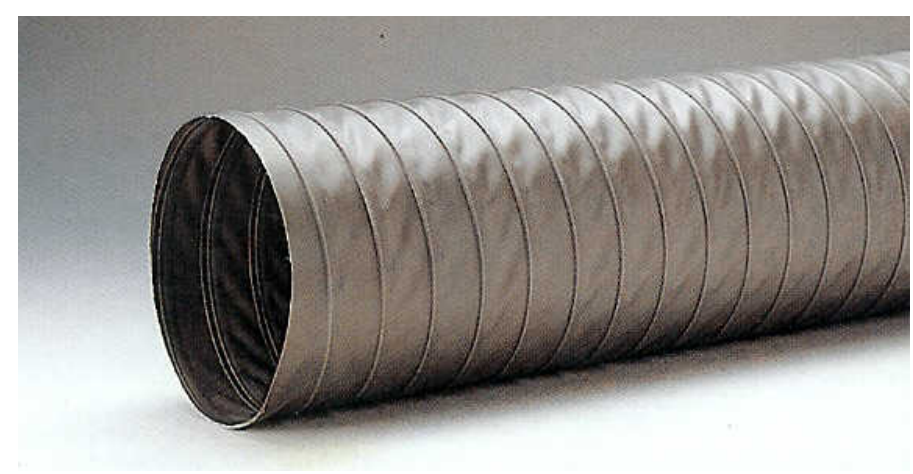

Figure 1. Typical flexible pipe.

Because of the specific construction, the pipe walls are not straight - they are corrugated. Moreover, the fabric which covers the steel spiral is much rougher than the wall of a smooth metal pipe. This requires more energy (higher pressure difference) to drive the flow. Therefore, an important factor in flexible pipe design is to attain minimum pressure loss throughout the distribution line and thus minimize the transportation costs. The pressure loss along a pipe is caused by the friction at the wall. In stationary flow, the friction is proportional to the pressure loss per unit distance [1]. Therefore, in this investigation, we are interested in estimating the friction factor for turbulent flow at Reynolds numbers around $10^{6}$ in a flexible pipe with a specific configuration. In particular, we study the influence of the roughness of the fabric on the friction factor. The performance of different two-equation turbulence models, boundary conditions and computational grids is investigated.

\section{MODELS AND BOUNDARY CONDITIONS FOR TUR- BULENT FLOWS}

There are basically three ways to simulate turbulent flow: Direct Numerical Simulation (DNS), Large-Eddy Simulation (LES) and Reynolds Averaged Navier-Stokes (RANS) models. Due to their randomness, turbulent flows are difficult to simulate. The more details we want to obtain from a simulation, the higher is the computational cost. DNS and LES offer a high degree of details, but require prohibitively large times for the flow simulations which are of interest to us. Given our purposes and the available computational power, we will use RANS models (specifically $k-\varepsilon$ and, to a lesser extent, $k-\omega$ ) for our simulations. The RANS equations are time- or ensemble-averaged equations of motion for fluid flow. The averaging process brings new unknown terms into the Navier-Stokes equation. Therefore, additional (closure) equations are needed to be able to solve the system. These equations are derived by taking higher-order moments of the averaged Navier-Stokes equation and making additional assumptions based on the knowledge of the properties of the turbulent flow. This process results in a modified set of equations that is computationally less expensive to solve. Below we give the equations which define the $k-\varepsilon$ model and the $k-\omega$ model [2].

\section{Mean flow equations.}

Mass conservation:

$$
\frac{\partial U_{j}}{\partial x_{j}}=0
$$

Momentum conservation:

$$
\rho\left[\frac{\partial U_{i}}{\partial t}+U_{j} \frac{\partial U_{i}}{\partial x_{j}}\right]=-\frac{\partial P}{\partial x_{i}}+\frac{\partial}{\partial x_{j}}\left[\left(\mu+\mu_{T}\right)\left(\frac{\partial U_{i}}{\partial x_{j}}+\frac{\partial U_{j}}{\partial x_{i}}\right)\right] .
$$

\section{Transport equations for standard $k-\varepsilon$ model.}

Turbulence energy equation:

$$
\rho \frac{\partial k}{\partial t}+\rho U_{j} \frac{\partial k}{\partial x_{j}}=\sigma_{i j} \frac{\partial U_{i}}{\partial x_{j}}-\rho \varepsilon+\frac{\partial}{\partial x_{j}}\left[\left(\mu+\frac{\mu_{T}}{\sigma_{k}}\right) \frac{\partial k}{\partial x_{j}}\right]
$$

Turbulence dissipation equation:

$$
\begin{aligned}
\rho \frac{\partial \varepsilon}{\partial t}+\rho U_{j} \frac{\partial \varepsilon}{\partial x_{j}} & =C_{\varepsilon 1} \frac{\varepsilon}{k} \sigma_{i j} \frac{\partial U_{i}}{\partial x_{j}}-C_{\varepsilon 2} \rho \frac{\varepsilon^{2}}{k} \\
& +\frac{\partial}{\partial x_{j}}\left[\left(\mu+\frac{\mu_{T}}{\sigma_{\varepsilon}}\right) \frac{\partial \varepsilon}{\partial x_{j}}\right]
\end{aligned}
$$

with $C_{\varepsilon 1}=1.44, C_{\varepsilon 2}=1.92, C_{\mu}=0.09, \quad \sigma_{k}=1.0, \sigma_{\varepsilon}=1.3$ and turbulent viscosity $\mu_{T}=\rho C_{\mu} \frac{k^{2}}{\varepsilon}$.

Transport equations for standard $k-\omega$ model.

Turbulence energy equation:

$$
\rho \frac{\partial k}{\partial t}+\rho U_{j} \frac{\partial k}{\partial x_{j}}=\sigma_{i j} \frac{\partial U_{i}}{\partial x_{j}}-\beta^{*} \rho k \omega+\frac{\partial}{\partial x_{j}}\left[\left(\mu+\sigma_{\omega}^{*} \mu_{T}\right) \frac{\partial k}{\partial x_{j}}\right] .
$$

Specific dissipation rate equation (the $\omega$-equation):

$$
\begin{aligned}
\rho \frac{\partial \omega}{\partial t}+\rho U_{j} \frac{\partial \omega}{\partial x_{j}} & =\alpha \frac{\omega}{k} \sigma_{i j} \frac{\partial U_{i}}{\partial x_{j}}-\beta \rho \omega^{2} \\
& +\frac{\partial}{\partial x_{j}}\left[\left(\mu+\sigma_{\omega} \mu_{T}\right) \frac{\partial \omega}{\partial x_{j}}\right],
\end{aligned}
$$


with $\alpha=\frac{5}{9}, \beta=\frac{3}{40}, \beta^{*}=\frac{9}{100}, \sigma_{\omega}=\frac{1}{2}, \sigma_{\omega}^{*}=\frac{1}{2}$ and $\mu_{T}=\rho \frac{k}{\omega}$. The following notation was used in the Equations (1)-(6):

$U_{i}$ - components of the velocity vector,

$x_{i}$ - components of the position vector,

$t$ - time,

$\rho$ - fluid density,

$P$ - pressure,

$\mu$ - viscosity,

$\mu_{T}$ - turbulent viscosity,

$k$ - turbulence kinetic energy,

$\varepsilon$ - turbulence dissipation,

$\omega$ - rate of dissipation per unit turbulence kinetic energy,

$\sigma_{i j}$ - Reynolds stress tensor, $\sigma_{i j}=\mu_{T}\left[\frac{\partial U_{i}}{\partial x_{j}}+\frac{\partial U_{j}}{\partial x_{i}}\right]$.

These models are given as defined by Wilcox in [2]. It is worth noting here that an updated and improved $k-\omega$ model has been presented in 2006 [3]. However, the earlier (standard) version of the $k-\omega$ model was the only option in the used software package.

The law of the wall. Because of the large velocity gradients arising in the region near the wall, this area requires special treatment. Moreover, the flow in the near-wall region is no longer turbulent (at least not everywhere) so that the assumptions made while deriving the turbulence models are not valid.

Traditionally, there are two approaches to modeling the flow in the near-wall region. In one approach, the turbulence models are modified to enable the viscosity-affected region to be resolved with a mesh all the way to the wall, including the viscous sublayer. In another approach, the viscosity-affected inner region (viscous sublayer and buffer layer) is not resolved. Instead, semi-empirical wall functions are used to bridge the viscosityaffected region between the wall and the fully-turbulent region. The use of wall functions obviates the need to modify the turbulence models to account for the presence of the wall. These two approaches are depicted schematically in Figure 2.

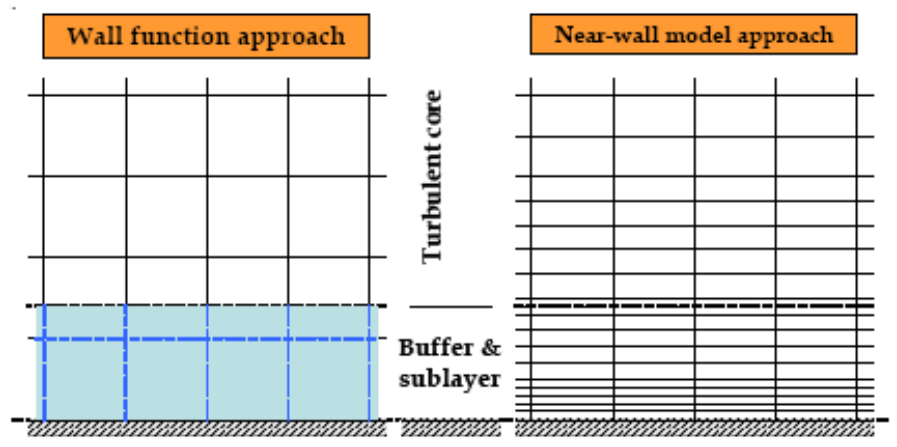

Figure 2. Schematic representation of the mesh for a wall function and a near-wall model approach.
In most high-Reynolds-number flows, the wall function approach substantially saves computational resources, because the viscosity-affected near-wall region, in which the solution variables change most rapidly, does not need to be resolved. The wall function approach is popular because it is economical, robust, and reasonably accurate. It is a practical option for the near-wall treatment in industrial flow simulations.

The boundary conditions derived from the wall functions (law of the wall) are applied at a location $y=y_{p}$ in the log-law region ( $y$ is the direction normal to the wall). We use the subscript ' $p$ ' to indicate quantities evaluated at $y_{p}$, such as $U_{p}, k_{p}$, $\varepsilon_{p}, \mu_{T p}$. The law of the (smooth) wall is given by the relation

$$
\begin{aligned}
& \frac{U_{p}}{u^{*}}=\frac{1}{\kappa} \ln \left(\frac{\rho u^{*} y_{p}}{\mu}\right)+B, \\
& \mathbf{n} \cdot \nabla k_{p}=0, \varepsilon_{p}=\frac{C_{\mu} k_{p}^{2}}{\kappa u^{*} y_{p}}, \omega_{p}=\frac{k_{p}}{\kappa u^{*} y_{p}},
\end{aligned}
$$

where $U_{p}$ is the tangential velocity, $u^{*}=C_{\mu}^{1 / 4} k_{p}^{1 / 2}$ is the shear velocity, $\kappa=0.41, B=5.0 \ldots 5.5$ and $\mathbf{n}$ is the unit vector normal to the wall. The value of $y_{p}$ is chosen such that $y_{p}^{+}=\rho u^{*} y_{p} / \mu$ is between 30 and 100. (i.e. in the range of the log-layer).

If the law of the wall would describe the velocity profile $e x$ actly, then, assuming a perfect turbulence model, the choice of $y_{p}^{+}$(in the range between 30 and 100) would not influence the solution. However, the law of the wall is a semi-empirical relation and the $k-\varepsilon / k-\omega$ models are based on assumptions which do not always hold. Therefore, the solution does depend on the thickness of the near-wall region. We hope though, that this dependence is not too strong (again, for $y_{p}^{+}$in the range between 30 and 100).

Simulations have been performed to observe the influence of the thickness of the near-wall region on the solution. The value $y_{p}^{+}$spans from 6.25 up to 3200 in a geometric progression. To measure the difference between solutions a certain norm could be used. However, since we are ultimately interested in friction factor estimation, we will use this as a physically relevant indicator.

Figure 3 shows the dependence of the friction factor on the thickness of the near-wall region at Reynolds number of order $10^{6}$. Although some preliminary simulations have shown a strong dependence of $f$ on $y_{p}^{+}[4]$, after individually adjusting the mesh (by using an adaptive solver) for each value of $y_{p}^{+}$, much better results have been obtained, as now shown in the plot. The friction factor is almost constant in the range of $y_{p}^{+}$between 50 and 300 (between the red vertical lines in the plot), where the variation of $f$ is less than $1.5 \%$. Thus, the range of validity of the law of the wall in combination with the $k-\varepsilon / k-\omega$ model proves to be in practice from 50 to 300 (instead of 30 to 100).

It must be mentioned that the logarithmic law of the wall is not indisputable. After all, Prandtl's assumption used in the 


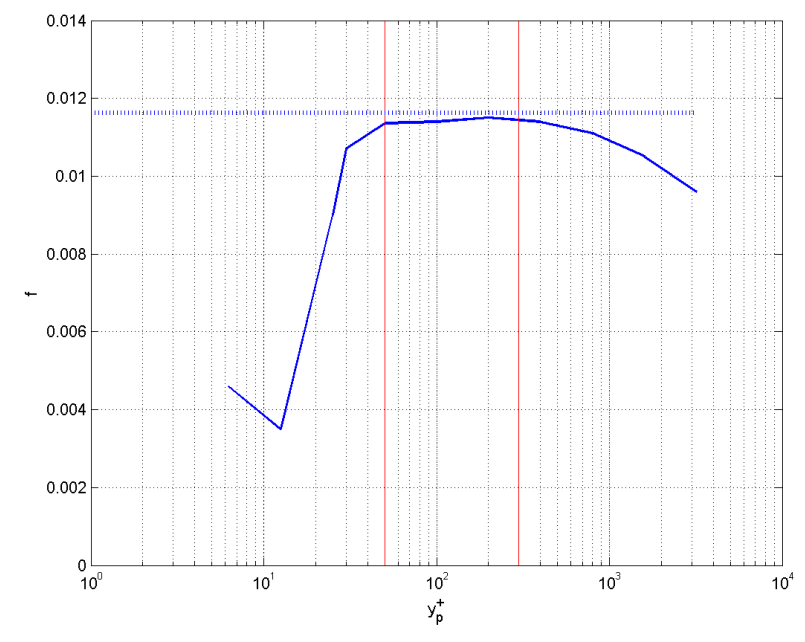

Figure 3. Dependence of the friction factor $f$ on the thickness $y_{p}^{+}$of the near-wall region at Reynolds numbers of order $10^{6}$. Solid line - computed values, dotted line - experimental values (from the Moody diagram). The $k-\varepsilon$ model is used.

derivation of the law is based only on dimensional grounds. The scaling in the inertial sublayer (also referred to as overlap region) of turbulent wall-bounded flows has long been the source of controversy. Barenblatt et al [5] developed theories showing that power laws are more suitable for describing velocity profiles in wall-bounded turbulent flows. Until recently this controversy could not be addressed because measurements did not span a sufficient range of Reynolds number. However, in 1997 new experiments conducted by Zaragola et al [6] have shown that at sufficiently high Reynolds numbers, the mean velocity profile in the overlap region is found to be better represented by a log law than a power law. These results suggest a theory of complete similarity instead of incomplete similarity, contradicting the theories developed by Barenblatt et al.

\section{FLOW SIMULATIONS FOR SMOOTH AND ROUGH NON-CORRUGATED PIPES}

In this section we evaluate the performance of two-equation RANS models as implemented in the Finite Element Package Comsol Multiphysics [7] and validate the boundary conditions based on the law of the wall which will be used later for more complex flows. To do this, we will simulate the turbulent flow in a pipe and assess the validity of the results by comparing the friction factor computed from the simulation to the one given by the Moody diagram. Models used in the simulations are $k-\varepsilon$ (Equations (1), (2), (3), (4)) and $k-\omega$ (Equations (1), (2), (5), (6)) written in cylindrical coordinates.
Computational domain geometry. The fully developed and time-averaged turbulent flow in a smooth pipe is onedimensional and axisymmetric in its nature, the only dimension being taken in the radial direction. In the following computations, a 2D axisymmetric model with periodic boundary conditions coupling inflow and outflow will be used. See Figure 4.

Boundary conditions. The Axial Symmetry boundary condition is prescribed at the centerline of the pipe. The other boundary parallel to the flow coincides with the wall of the pipe. Along this boundary, the law of the wall (7) is used to prescribe the axial velocity at a certain distance from the wall.

An effective method of simulating fully developed flow on a small computational domain is the use of periodic boundary conditions. Their use is explained by the fact that the fully developed flow has a constant velocity profile, which means that:

$$
\begin{aligned}
U_{1}(r, 0) & =U_{1}(r, L), \\
U_{2}(r, 0) & =U_{2}(r, L), \\
k(r, 0) & =k(r, L), \\
\varepsilon(r, 0) & =\varepsilon(r, L), \\
\omega(r, 0) & =\omega(r, L) .
\end{aligned}
$$

where $L$ is the length of the computational domain in the axial direction (set as $L=0.02 \mathrm{~m}$ ).

At inflow and outflow boundaries we will prescribe constant pressures $P(r, 0)=P_{\text {in }}$ and $P(r, L)=P_{\text {out }}$, where $P_{\text {out }}$ is taken to be zero. We are entitled to do this because in a fully developed flow through a duct with constant shape cross-section the transverse velocity components vanish and it can be easily proven from the momentum conservation equation (2) that

$$
\frac{\partial P}{\partial r}=0 \Rightarrow P(r)=\text { constant }
$$

Meshing and solution procedure. Although our computational domain is very regular, which encourages the use of structured meshes, it was decided to use unstructured grids (based on Delaunay triangulation) for the discretization step because we want to use similar grids for both corrugated and noncorrugated pipes, and only unstructured grids can be used for the latter. The solution procedure consists of three steps:

- Solve the model on a coarse mesh.

- Refine the mesh by subdivision to obtain the one shown in Figure 4.

- Solve the model on the refined mesh, using the coarse mesh solution as an initial guess. 
outflow

centerline wall

inflow

Figure 4. Computational domain and the fine mesh used for the last step of the computations.

This strategy proved to be faster than immediately solving the model on the refined mesh. After the solution was obtained it was additionally checked by uniformly refining the mesh once again and comparing the new solution to the previous one. The difference between them was in all cases less than $2 \%$.

\subsection{Smooth Wall Validation}

To validate the simulation of turbulent flow in pipes with smooth walls, a postprocessing procedure is performed at the end of each simulation. Average velocity $V_{a v g}$, Reynolds number $R e$ and the Darcy-Weisbach friction factor $f$ are computed as follows:

$$
V_{a v g}=\int_{0}^{R} \frac{U_{1} 2 \pi r}{\pi R^{2}} d r, \quad R e=\frac{2 R \rho V_{a v g}}{\mu}, \quad f=\frac{2 R \Delta P}{0.5 \rho V_{a v g}^{2} L},
$$

where $\Delta P$ is the prescribed difference in pressure between in- and outflow, $R$ is the radius of the pipe and $L$ is the length of the pipe section included in the computational domain.

It is worth mentioning here that, because of the way the law of the wall is used as a boundary condition in Comsol Multiphysics, the computational domain does not include the whole physical domain. Specifically, it does not include the thin layer near the wall where the velocity profile is given by the law of the wall (the shaded area in Figure 2). Therefore, in Equation (11), the radius $R$ should be understood as $R=R^{\prime}+y_{p}$, where $R^{\prime}$ is the radius of the pipe in the simulations. In the computations the following values have been used: $R^{\prime}=0.2 \mathrm{~m}, L=0.02 \mathrm{~m}$.

Simulations have been performed for a wide range of Reynolds numbers (from $10^{4}$ up to $10^{8}$ ), using the two turbulence models $(k-\omega$ and $k-\varepsilon)$. For each model, two different values of $B$ (5.5. and 5.0) were used in the boundary condition given by Equation (7).

Thus, for each Reynolds number, we end up with four computed friction factors plus the friction factor taken from the Moody diagram. These are shown in Figure 5. As can be seen from the plot, in the range of (relatively) low Reynolds numbers $\left(10^{4}\right.$ to $\left.10^{5}\right)$ the computed values are far from the measured friction factor. The $k-\varepsilon$ model seems to perform better in this range of $R e$. For higher Reynolds numbers, that is fully developed turbulence, the computed values follow closely the measured value; for $R e>5 \times 10^{5}$ the relative error is less than 0.04 . Now the

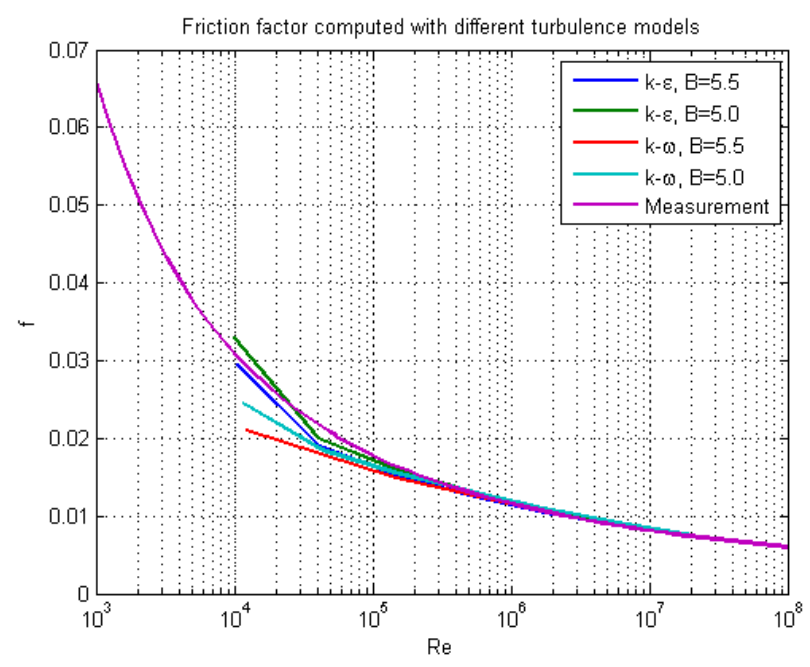

Figure 5. Computed and measured friction factors for smooth pipes $(e / D=0)$.

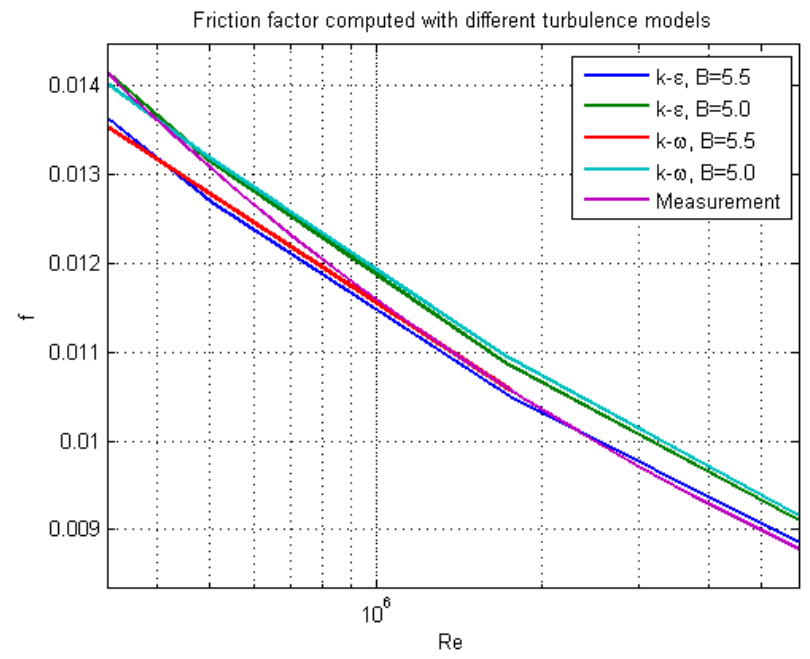

Figure 6. Computed and measured friction factors for smooth pipes $(e / D=0)$ zoomed around $R e \sim 10^{6}$.

$k-\varepsilon$ and $k-\omega$ models perform equally well and the choice of $B$ in the boundary condition becomes important. As seen from Figure 6 (showing the plot from Figure 5 zoomed around $R e=10^{6}$ ), for $R e \leq 7 \times 10^{5}$ simulations with $B=5.0$ give closer agreement with the measured friction factor, while for $\operatorname{Re}>7 \times 10^{5}$ the friction factor is better predicted by the simulations with $B=5.5$. This could be the reason why different authors give slightly different values for $B$ in the law of the wall; its choice depends on the Reynolds number characteristic to the flow. 


\subsection{Rough Wall Modeling and Validation}

The asperities on the pipe wall become important when their size is comparable to the thickness of the laminar sublayer. Roughness effects can be accounted for by using a law of the wall modified for roughness. If $e$ is the equivalent height of the asperities, the law of the (rough) wall is given by the relation (see e.g. [2]):

$$
\frac{U}{u^{*}}=\frac{1}{\kappa} \ln \left(\frac{y_{p}}{e}\right)+8.5 .
$$

Figure 7 shows the friction factors computed using the law above. We observe that this law provides a good prediction of the friction factor only for Reynolds numbers higher than $10^{6}$ and is totally wrong for Reynolds numbers lower than $10^{5}$. To get a good approximation for the whole spectrum of Reynolds numbers, we need to combine the law for smooth walls with the law for rough walls.

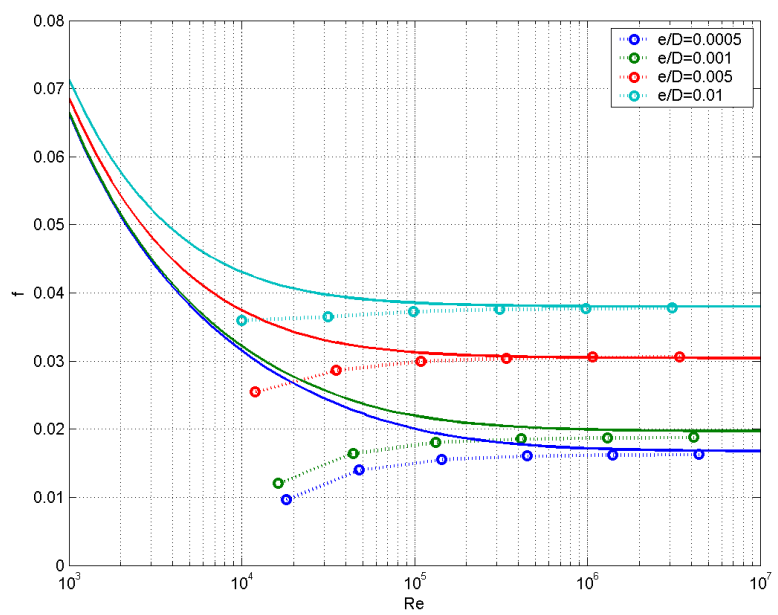

Figure 7. Computed (dotted lines) and measured (solid lines) friction factors for flow in pipes with rough walls. The $k-\varepsilon$ model is used.

Experiments in roughened pipes and channels indicate that the mean velocity distribution near rough walls, when plotted in the usual semi-logarithmic scale, has the same slope $(1 / \kappa)$ but a different intercept (additive constant $B$ in the log-law). Thus, the law-of-the-wall for mean velocity modified for roughness has the form [8]

$$
\frac{U}{u^{*}}=\frac{1}{\kappa} \ln \left(\frac{\rho u^{*} y_{p}}{\mu}\right)+B^{*},
$$

where $B^{*}$ is a roughness function that quantifies the shift of the intercept due to roughness effects.

For sand-grain roughness and similar types of uniform roughness elements, $B^{*}$ has been found to be well-correlated with the nondimensional roughness height, $e^{+}=\rho e u^{*} / \mu$. Analysis of experimental data for uniform roughness shows that the roughness function, $B^{*}$, is not a single function of $e^{+}$, but takes different forms depending on the $e^{+}$value. It has been observed that there are three distinct regimes:

- Hydrodynamically smooth $\left(e^{+}<e_{1}^{+}\right)$

- Transitional $\left(e_{1}^{+}<e^{+}<e_{2}^{+}\right)$

- Fully rough $\left(e^{+}>e_{2}^{+}\right)$

where $e_{1}^{+} \sim 3 \ldots .5$ and $e_{2}^{+} \sim 70 \ldots 90$.

According to the data, roughness effects are negligible in the hydrodynamically smooth regime, but become increasingly important in the transitional regime, and take full effect in the fully rough regime. The formulas proposed by Ioselevich and Pilipenko in [8] are adopted to compute the roughness function, $B^{*}$, for each regime.

$$
B^{*}=B+\theta\left(8.5-B-\frac{1}{\kappa} \ln e^{+}\right), \text {with } B=5.5 .
$$

The case of hydrodynamic smoothness corresponds to $\theta=0$ $\left(e^{+}<e_{1}^{+}\right)$, whereas the case of full roughness corresponds to $\theta=1\left(e^{+}>e_{2}^{+}\right)$. The function $\theta=\theta\left(e^{+}\right)$for $e_{1}^{+}<e^{+}<e_{2}^{+}$is obtained in [8] from the analysis of experimental data. The following approximation is proposed for $\theta$ :

$$
\theta=\sin \left(\frac{\pi}{2} \frac{\ln \left(e^{+} / e_{1}^{+}\right)}{\ln \left(e_{2}^{+} / e_{1}^{+}\right)}\right)
$$

The values for $e_{1}^{+}$and $e_{2}^{+}$recommended by Ioselevich and Pilipenko are 2.25 (although outside of the prescribed interval, in practice this value gives optimal results) and 90, respectively. These values were used in the present investigation. Thus we have:

$$
\theta= \begin{cases}0, & e^{+}<2.25 \\ \sin \left[0.4258\left(\ln e^{+}-0.811\right)\right] & e^{+} \in[2.25,90] \\ 1, & e^{+}>90\end{cases}
$$

Given the roughness parameter, the roughness function $B^{*}\left(e^{+}\right)$is evaluated using (14) and the corresponding formula for $\theta$ (Equation (16)). The modified law of the wall in Equation (13) is then used to evaluate the velocity at the wall. 
Figure 8 shows the results of the computations. They were obtained by varying two parameters of the flow: pressure difference, $\Delta P=\{0.1,1,10,100,1000,10000\} \mathrm{Pa}$ and relative roughness, $\frac{e}{2 R}=\{0.0005,0.001,0.005,0.01,0.05\}$. The pressure variation determines the variation of the Reynolds number, while the change of relative roughness generates a set of distinct curves on the diagram. Dotted lines indicate the computed friction fac-

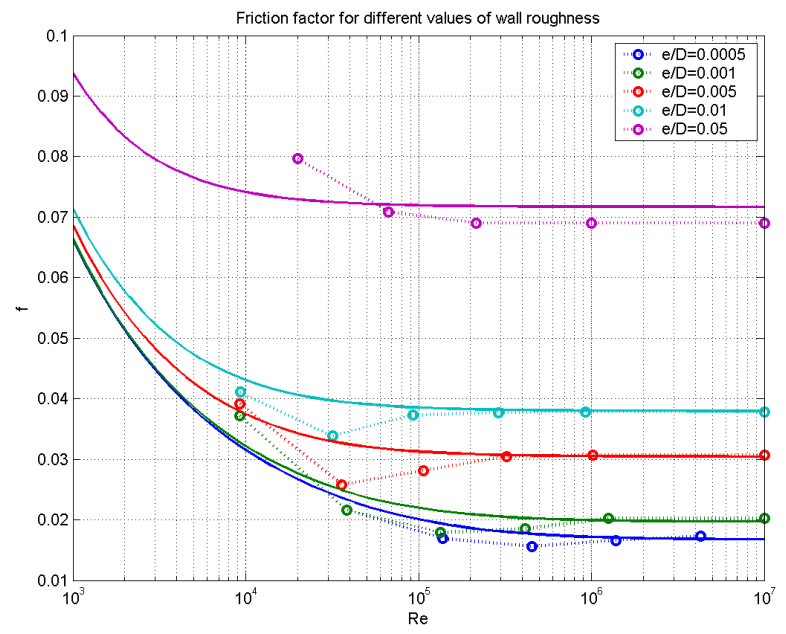

Figure 8. Computed (dotted lines) and measured (solid lines) friction factors for flow with rough walls using a "combined" law of the wall, Equations (13), (14), (16). The $k-\varepsilon$ model is used.

tor, while solid lines correspond to the friction factor obtained from the Moody diagram. There is an excellent agreement of measured and computed values for $R e>10^{6}$. In the transitional regime $\left(10^{4}<\operatorname{Re}<10^{5}\right)$, however, the friction factor seems to be underpredicted by our model. It is noticed that our computations resemble the measurements of Nikuradse [9]. Nikuradse's diagram is in essence identical to the Moody diagram, with a small difference in the transitional regime. This difference is caused by the fact that the transition from hydraulically smooth conditions at small Reynolds numbers to complete roughness at large Reynolds numbers occurs much more gradually in commercial rough pipes (used by Moody) than in artificially roughened pipes (used by Nikuradse).

Our computations resemble the data from Nikuradse, because the latter was used by Ioselevich and Pilipenko [8] to fit the "combined" law of the wall (Equations (13), (14) and (16)).

\section{FLOW SIMULATIONS FOR CORRUGATED PIPES}

As it was explained in the Introduction, flexible ducts have a specific structure. To enable simulation of the flow in $2 \mathrm{D}$, the steel spiral is modeled as an annular corrugation and not as a helical one. Helical corrugation requires more demanding 3D simulations and is studied in [10].

The flow inside corrugated pipes has some important properties which are not characteristic to flows in conventional pipes. One of the expected effects of corrugation is that the transition from laminar to turbulent flow will occur at lower Reynolds numbers (so, at $R e<2000$ ). Nishimura et al [11], Russ and Beer [12], and Yang [13] investigated the transitional flow characteristics in corrugated ducts. Indeed, they reported the laminar-turbulent transition to occur at very low Reynolds numbers compared with conventional ducts. Another important characteristic of flow in corrugated pipes is the possible presence of local adverse pressure gradients and, as a result, the appearance of flow separations.

The objective in this section is to set up a model in Comsol Multiphysics which will allow us to perform a set of simulations and compute the friction factor depending on parameters such as roughness of the hose wall. Before we perform the simulations, a proper turbulence model has to be chosen $(k-\varepsilon, k-\omega$, or both). Because of the curved surfaces present in the geometry, we expect to encounter separated flow. Prediction of separated flows is an "Achilles heel" for many turbulence models [14], therefore simulations of turbulent flow over a backward facing step (a standard test problem for separated flow) have been performed using $k-\varepsilon$ and $k-\omega$ turbulence models. Results, presented in [4], have shown that although both models underpredict the reattachment length, the values given by the $k-\varepsilon$ model are closer to experimental data. Therefore, we have chosen the $k-\varepsilon$ model, given by Equations (1 - 4), for our computations.

Computational domain geometry. In general, fully developed turbulent flow in a helically corrugated pipe is of three-dimensional nature. For the annular corrugation considered, it can be reduced to $2 \mathrm{D}$ because of axial symmetry. In other words, characteristics of the flow only depend on the distance from the pipe's centerline, $r$, and the position along the pipe, $x$, within a single period.

Figure 9 shows the computational domain for the simulated pipe. It includes one period of the corrugated pipe. At the left and at the right it is bounded by the wall and by the symmetry axis, respectively, while the inflow/outflow boundaries are the ones located at the top and bottom of the domain. The radius of the spiral is $1 \mathrm{~cm}$.

Boundary conditions. As can be seen from Figure 9, our computational domain has five distinct boundaries at which boundary conditions have to be prescribed. Axial Symmetry is prescribed at the centerline of the pipe. The other boundary parallel to the flow coincides with the wall of the pipe, which consists of two different materials: a flexible hose made of fabric and 
a steel spiral. The spiral, made of steel, is considered a smooth surface. Therefore, the standard law of the wall (7) is used there. The part made of fabric, on the other hand, is considered to be rough, so the "combined" law of the wall modified for roughness (13) is used.

The boundaries normal (perpendicular) to the flow represent inflow and outflow boundaries. Far from the duct entrance, the flow will be periodically fully developed [15] because of the equidistant positioning of the corrugations. In a periodic fully developed flow, the velocity repeats itself at corresponding axial locations in successive cycles. Now it becomes clear why it is enough to confine the computational domain to a single period (cycle) of the corrugation and use again the periodic boundary conditions defined by Equations (9).

Now remains the question of the conditions for the pressure at the inflow/outflow boundaries. In the periodic fully developed regime, the pressure at periodically corresponding locations decreases linearly in the downstream direction [16]. Thus, the pressure $P$ can be expressed as

$$
P(x, r)=-\beta x+p^{\prime}(x, r)
$$

where $\beta$ is the mean pressure gradient and $p^{\prime}(x, r)$ is the periodic component of the pressure. The term $-\beta x$ represents the nonperiodic pressure drop that takes place in the flow direction. Keeping in mind that $p^{\prime}\left(x_{i n}, r\right)=p^{\prime}\left(x_{\text {out }}, r\right)$, we have

$$
P\left(x_{\text {in }}, r\right)-P\left(x_{\text {out }}, r\right)=\beta\left(x_{\text {out }}-x_{\text {in }}\right)=\beta L .
$$

Because $\beta$ is the mean pressure gradient, we have that $\beta L=\Delta P$, with $\Delta P$ being the pressure difference between the inflow and outflow boundaries. Thus, we obtain the desired periodic boundary condition for $P$ :

$$
P\left(x_{\text {in }}, r\right)=P\left(x_{\text {out }}, r\right)+\Delta P
$$

with $\Delta P$ given.

Meshing and solution procedure. We expect large gradients around the corrugation, which require refined meshes. As the exact position of high activity regions depends on the parameters of the flow, adaptive mesh generation is used. It is characterized by the fact that the construction of the mesh and the calculation of the corresponding solution are performed simultaneously. This technique identifies the high-activity regions that

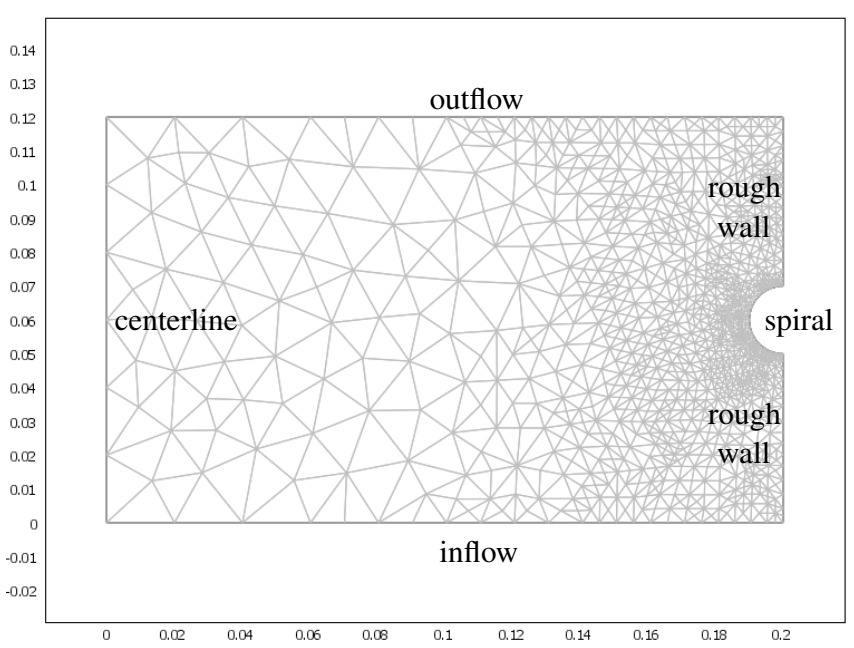

Figure 9. Computational domain with the adapted mesh (generated from an initial mesh by an adaptive solver). Distances are in meters.

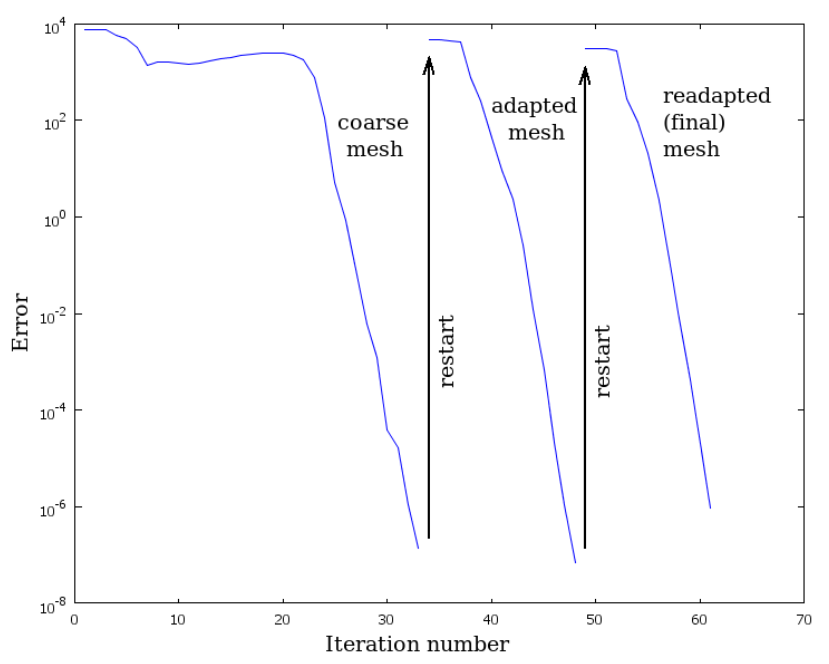

Figure 10. Numerical error vs. total iteration number. Each curve corresponds to a mesh and has its local origin at the end of the previous curve.

require a high resolution (by estimating the errors) and produces an appropriate mesh.

To perform the simulations an adaptive solver was used. A coarse mesh was used as a starting point. It was adaptively refined by the solver to finally arrive at the mesh shown in Figure 9. We notice that the regions around the corrugation and near the wall require much higher resolution than the area near the center of the pipe.

Figure 10 shows the convergence of the solution when us- 
ing the adaptive solver. First, the model is solved on the coarse mesh. Then the errors are estimated and the mesh is refined at the locations with the larger errors. The model is solved again on the new mesh. The process continues until the errors are smaller than a certain threshold and the maximum number of mesh refinements is reached (this number is 2 in our case).

Discussion of solution. A typical solution for the case of periodically fully developed turbulent flow in a corrugated pipe (at $R e \approx 10^{6}$ ) is displayed in Figure 11 . The colored surface corresponds to the value of pressure, arrows indicate the direction and the magnitude of the velocity field, while the green lines near the wall are the streamlines of the flow. As expected, there is a region of higher pressure upstream the bump (corrugation), followed by a region of lower pressure downstream. By doing several computations for different Reynolds numbers it became clear that the low-pressure region is located behind the bump in flows at low Reynolds number, and it moves towards the top of the bump as the Reynolds number becomes larger. There is an adverse pressure gradient on the top of the bump. However, due to the large enough velocity, the flow has sufficient momentum to overcome it and keep flowing in the mainstream direction. The situation is not the same for the flow immediately behind the bump. A continuous retardation of flow brings the velocity (as well as its gradient and the wall shear stress) near a certain point on the wall to zero. From this point onwards the flow reverses and a region of recirculating flow develops. The shear stress becomes negative. We see that the flow no longer follows the contour of the wall. The flow has separated. The point where the shear stress is zero is the point of separation. Further downstream the recirculating flow terminates and the flow becomes reattached to the wall. Thus, a separation of the flow occurs and a recirculation zone (a vortex) is formed.

The cross-sectional pressure profile is shown in Figure 12. It is no longer constant as it was the case for a non-corrugated pipe. The pressure is almost constant near the centerline and strongly increases towards the corrugated wall, where higher resistance is encountered.

\section{Influence of fabric roughness on the friction fac-}

tor. One of the goals of this investigation was to answer the question whether the type of the fabric (which is wrapped around the steel spiral) has a strong influence on the friction factor for the resulting pipe. In order to do this, simulations were performed for a set of values for relative roughness of the fabric, $e / D=\{0,0.0125,0.025,0.05\}$. The computed friction factors (see Equation (11)) are shown in Table 1.

Two observations can be made here: (a) the friction factor increases as the relative roughness increases (this is what we expect) and (b) the increase is small.

The difference between the two limiting cases $e / D=0$ and

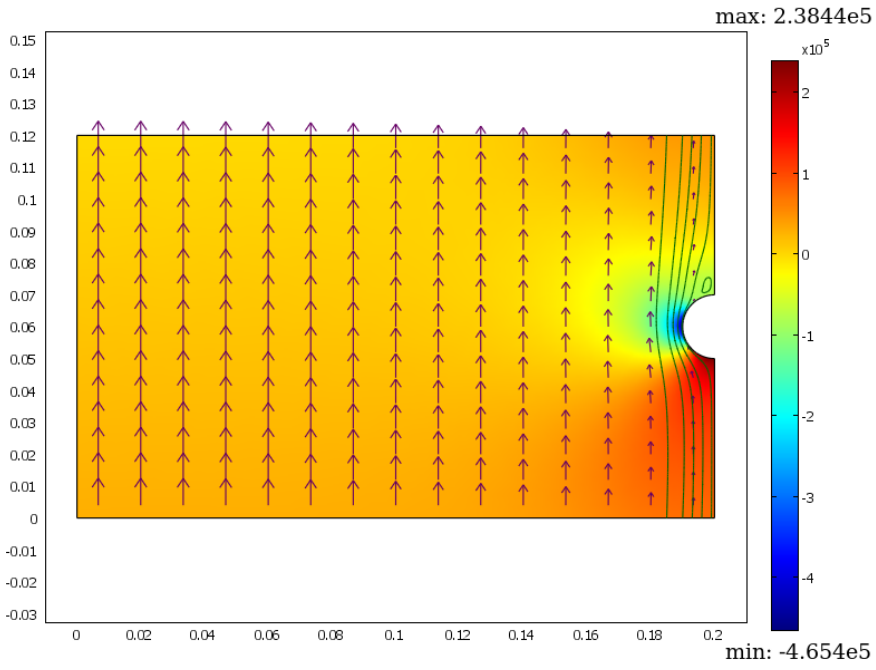

Figure 11. A typical solution. Colored surface - pressure, arrows - velocity field, green lines - streamlines. This computation was performed for $\Delta P=3 \cdot 10^{4} \mathrm{~Pa}, \rho=500 \mathrm{~kg} / \mathrm{m}^{3}, \eta=0.01 \mathrm{~Pa} \cdot \mathrm{s}$.

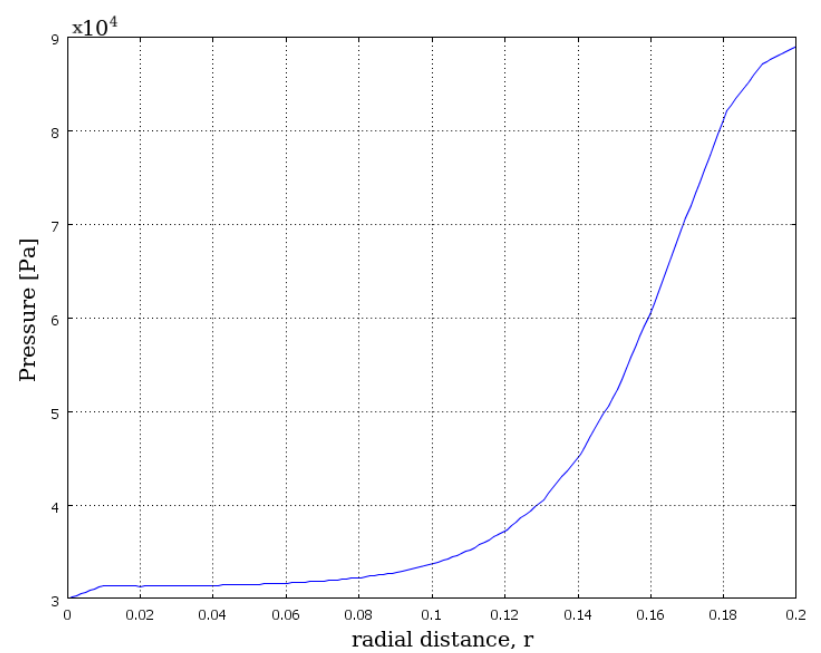

Figure 12. Pressure profile along the radial direction at $x=0$.

$e / D=0.05$ is less than $10 \%$. This entitles us to state that the roughness of the fabric has a negligible influence on the friction factor. There is no point in looking for new materials which would keep the properties of the older ones (such as noninflammable, resistive to high pressures, resistive to extreme temperatures, etc.) but would have a lower roughness, because the decrease in the friction factor is predicted to be too small to be of practical value. 


\begin{tabular}{|r|l|l|l|l|}
\hline$e / 2 R$ & 0 & 0.0125 & 0.025 & 0.05 \\
\hline$f$ & 0.140 & 0.146 & 0.148 & 0.152 \\
\hline
\end{tabular}

Table 1. Friction factor vs. fabric roughness.

\section{CONCLUSIONS}

The performance of two-equation turbulence models (RANS) was assessed. Two popular representatives of this class were investigated: the $k-\varepsilon$ and the $k-\omega$ models. They have been tested for smooth and rough pipe flow. The pipe flow simulations have shown that both models perform reasonably well, with a small advantage of the $k-\varepsilon$ model over the $k-\omega$ model at low Reynolds numbers $\left(10^{4}<R e<10^{5}\right)$. Also, it has been shown that the experimental results are closer reproduced if the constant $B$ in the law of the wall has a value of 5.0 for $R e \leq 7 \times 10^{5}$ and 5.5 for $R e>7 \times 10^{5}$. Tests with flow over a backward-facing step have confirmed the tendency of two-equation models to underpredict the reattachment length [4]. However, the results obtained from the $k-\varepsilon$ model were closer to the measurements. For this reason, the $k-\varepsilon$ model was chosen for the simulation of fully developed turbulent flow in corrugated pipes, where flow separation is encountered in between the corrugations.

The effects of wall roughness have been modeled by implementing a new boundary condition based on a combined law of the wall. The flow in a non-corrugated (conventional) pipe with rough walls, for which experimental data exists, was used as a test problem. The results of the test reproduce approximately the Moody diagram (except for a small range of $R e$ around $10^{5}$ ) and are in close agreement with Nikuradse's experimental data.

Trusting our models and boundary conditions, the question whether the type of the fabric used in the corrugated pipe has a strong influence on the friction factor was investigated. The performed computations have shown that for this specific geometry the roughness of the fabric has a small influence on the friction factor. This in turn means that no considerable advantage is gained by replacing a rough fabric by a smooth one. The bumps created by the steel spiral cause most resistance and considerable drag reduction can only be obtained by optimizing their shape.

\section{REFERENCES}

[1] Herwig, H., Gloss, D., and Wenterodt, T., 2008. "A new approach to understand and model the influence of wall roughness on friction factors for pipe and channel flows". Journal of Fluid Mechanics, 613, pp. 35-53.

[2] Wilcox, D. C., 1998. Turbulence Modeling for CFD, 2nd edition. DCW Industries, Inc., La Cañada, California.

[3] Wilcox, D. C., 2006. Turbulence Modeling for CFD, 3nd edition. DCW Industries, Inc., La Cañada, California.
[4] Pisarenco, M., 2007. "Friction factor estimation for turbulent flows in corrugated pipes with rough walls". Master's thesis, Eindhoven University of Technology.

[5] Barenblatt, G. I., Chorin, A. J., and Prostokishin, V. M., 1997. "Scaling laws for fully developed turbulent flow in pipes: discussion of experimental data". Proceedings of the National Academy of Sciences of the USA, 94(3), pp. 773776.

[6] Zagarola, M., Perry, A., and Smits, A., 1997. "Log laws or power laws: The scaling in the overlap region". Physics of Fluids, 9(7), pp. 2094-2100.

[7] COMSOL Multiphysics. Chemical Engineering Module, User's Guide. COMSOL AB, 2006.

[8] Ioselevich, V. A., and Pilipenko, V. N., 1974. "Logarithmic velocity profiles for flow of a weak polymer solution near a rough surface". Soviet Physics Doklady, 18, pp. 790-796.

[9] Nikuradse, J., 1937. "Laws of flow in rough pipes". NACA Tech. Mem. 1292.

[10] van der Linden, B., Pisarenco, M., Ory, E., Dam, J., and Tijsseling, A., 2009. "Efficient computation of threedimensional flow in helically corrugated hoses including swirl". Proc. of the 2009 ASME Pressure Vessels and Piping Division Conf., Prague, Czech Republic, July 2009, Paper PVP2009-77997. Accepted.

[11] Nishimura, T., Ohori, Y., and Kawamura, Y., 1984. "Flow characteristics in a channel with symmetric wavy wall for steady flow". J. Chem. Eng. of Japan, 17, pp. 466-471.

[12] Russ, G., and Beer, H., 1997. "Heat transfer and flow field in a pipe with sinusoidal wavy surface - I. Numerical investigation". Int. J. Heat Mass Transfer, 40(5), pp. 1061-1070.

[13] Yang, L. C., 1997. "Numerical prediction of transitional characteristics of flow and heat transfer in a corrugated duct". J. Heat Transfer, 119, pp. 62-69.

[14] Patel, V. C., 1998. "Perspective: Flow at high Reynolds number and over rough surfaces - Achilles heel of CFD”. Journal of Fluids Engineering, 120, pp. 434-444.

[15] Patankar, S. V., Liu, C., and Sparrow, E. M., 1977. "Fully developed flow and heat transfer in ducts having streamwise-periodic variations of cross-sectional area". $J$. Heat Transfer, 99, pp. 180-186.

[16] Ergin, S., Ota, M., and Yamaguchi, H., 2001. "Numerical study of periodic turbulent flow through a corrugated duct". Numerical Heat Transfer, 40, pp. 139-156. 
PREVIOUS PUBLICATIONS IN THIS SERIES:

\begin{tabular}{|c|c|c|c|}
\hline Number & Author(s) & Title & Month \\
\hline $09-11$ & A.Muntean & $\begin{array}{l}\text { Large-time behavior of } \\
\text { solutions to a reaction- } \\
\text { diffusion system with } \\
\text { distributed microstructure }\end{array}$ & March '09 \\
\hline 09-12 & L.M.J. Florack & $\begin{array}{l}\text { Coarse-to-fine partitioning of } \\
\text { signals }\end{array}$ & March '09 \\
\hline $09-13$ & $\begin{array}{l}\text { J.A.W.M. Groot } \\
\text { C.G. Giannopapa } \\
\text { R.M.M. Mattheij }\end{array}$ & $\begin{array}{l}\text { Numerical optimisation of } \\
\text { blowing glass parison shapes }\end{array}$ & March '09 \\
\hline $09-14$ & A.S. Tijsseling & $\begin{array}{l}\text { Exact computation of the } \\
\text { axial vibration of two coupled } \\
\text { liquid-filled pipes }\end{array}$ & May '09 \\
\hline $09-15$ & $\begin{array}{l}\text { M. Pisarenco } \\
\text { B.J. van der Linden } \\
\text { A.S. Tijssseling } \\
\text { E. Ory } \\
\text { J.A.M. Dam }\end{array}$ & $\begin{array}{l}\text { Friction factor estimation for } \\
\text { turbulent flows in corrugated } \\
\text { pipes with rough walls }\end{array}$ & May '09 \\
\hline
\end{tabular}

